\title{
Frozen Foods and Recommended Packaging Temperatures
}

\author{
Evan Sudiono ${ }^{1}$, Bobby Sidhu' ${ }^{2}$, Helen Heacock ${ }^{3}$, Lorraine McIntyre ${ }^{4}$ \\ 1 Lead author, B. Tech Student, School of Health Sciences, British Columbia Institute of Technology, 3700 Willingdon Ave, Burnaby, BC, \\ V5G $3 \mathrm{H} 2$ \\ 2 Supervisor, School of Health Sciences, British Columbia Institute of Technology, 3700 Willingdon Ave, Burnaby, BC, V5G 3H2 \\ 3 Contributor, British Columbia Center for Disease Control, 655 West 12th Avenue, Vancouver, BC V5Z 4R4
}

\begin{abstract}
Background: Frozen foods have cooking instructions on their packaging, but due to foodborne illnesses resulting from consuming them, it brings the effectiveness of these instructions into question. The recommended cooking temperature on the packaging is a specific numerical value that is not open to interpretation and can be used to measure effectiveness.

Methods: Temperatures were taken from 208 different meat products from different stores. The information recorded include: the store the products were found at, the type of meat, whether the product was uncooked or cooked, and if it had safe handling instructions. The data was compared to 3 different guidelines to see if they met the recommendations or not. The results of the comparison were then analyzed using Chi-squared tests.

Results: A majority of T\&T products failed in all 3 standards, the majority of products from Superstore passed using all 3 standards, and the majority of products from Costco failed using 2 standards.

Conclusion: The amount of products that met recommendations is dependent on the store, the type of meat, the uncooked or cooked status, and the guidelines being used due to the recommended temperature of poultry being vastly different in one of the guidelines. The other products that did not meet recommendations were due to them being cooked products without a recommended reheating
\end{abstract}

Keywords: Temperature, microwave, Regulations, Food Code, meat product, guidelines

\section{Introduction}

In 2004, a Salmonellosis outbreak was caused by consumers eating raw chicken nuggets that were inadequately cooked. In 2007, a similar outbreak occurred from consumers eating inadequately reheated frozen pot pies. In 2010, another Salmonellosis outbreak was caused by consumers eating inadequately reheated frozen meals. Unclear instructions on the packaging were one of the common factors involved in all three outbreaks. The chicken nuggets in the 2004 outbreak looked ready to eat when they were raw, and the pot pies and frozen dinners were mostly microwaved, which would not reach an adequate reheating temperature of $74^{\circ} \mathrm{C}$ to properly kill pathogens (Fayerman, 2004).

\section{Legislation}

The Federal Meat Inspection Regulations is the legal document that instructs producers what to put on their product packaging on meat products (CFIA, 2013a). In response to the 2004 outbreak, changes have been made to the regulations. These changes include Section 94, Subsection 6.1 (a), which deals with the labeling of products that only appear ready-to-eat on the packaging (2013a). The Act requires producers to label a product as 'raw', 'uncooked', or must say that it requires cooking.Subsection 6.1 (b), provides an 
outcome based requirement that instructs the producer to give customers 'comprehensive' instructions with a time and temperature relationship that will result in the product becoming safe for consumption if the instructions are followed correctly (BCCDC, 2008).

\section{Guidelines}

To help decrease the ambiguity of the Meat Inspection Regulations' outcome-based requirements, several guidelines may have been used by manufacturers to set their recommended temperatures. This study looked at the Canadian Food Services and Food Retail Code, Foodsafety.gov, and the Government of Canada's guidelines for recommended temperatures of various foods (CFISIG, 2004; Foodsafety.gov, 2014; Government of Canada, 2014). These guidelines all have similar temperatures, but the Food Code specifically gives poultry a recommended cooking temperature of $85^{\circ} \mathrm{C}$, while Foodsafety.gov gives $74^{\circ} \mathrm{C}$. The Government of Canada guidelines do separate poultry to whole and pieces of poultry Whole poultry is recommended to have an internal temperature of $85^{\circ} \mathrm{C}$ while pieces of poultry are recommended to have $74^{\circ} \mathrm{C}$. The Food Code is also the only guideline to provide a recommended reheating temperature of $74^{\circ} \mathrm{C}$.

\section{Similar research}

To see if manufacturers are following the new requirements in the Regulations, BCCDC launched a study on 24 various frozen chicken nugget products in 2008 (BCCDC, 2008). Most recommended temperatures fall between 71 to $77^{\circ} \mathrm{C}$, with $74^{\circ} \mathrm{C}$ being the most common. All the products they checked also showed the 'uncooked' label, and had food safe handling instructions. Another aspect of the study BCCDC performed is to see how many of these products were contaminated with E. coli, of which 6 were contaminated, and how many had Salmonella, of which 2 were contaminated. While Salmonella seems to be the common thread between the above events, other pathogens may inhabit frozen products as well, which will require proper reheating and cooking to kill. Listeria and Campylobacter are also pathogens that could be found in frozen meat products (BCCDC, 2012a, 2012b). All three pathogens can be killed by properly cooking or reheating food to the appropriate temperatures.

This study looks at what factors of the food affects whether the recommended temperature on the packaging will be adequate or not by comparing them to the three guidelines mentioned above. Whether the product is uncooked or cooked, the type of meat the product is, the store the product was found in, and which guideline the recommended temperature is being compared to are the 4 factors that were tested on the 208 products surveyed in this study.

\section{Methods}

In three different stores in the Lower Mainland, the researcher recorded the recommended temperatures of 208 frozen meat products, 57 of which were from Costco, 110 from Superstore, and 41 from T\&T. Also recorded for each product were whether the product was cooked or uncooked, if the type of meat was ground meat, poultry, beef, pork, or seafood, and whether the product had safe handling instructions or not. The data was then logged onto a Microsoft Excel spreadsheet, and the recorded temperatures were then compared to each of the three guidelines mentioned above. Products with recommended temperatures that are equal to or greater than the guideline values received a pass, while those with below the guideline value or no recommended temperatures received a fail.

As Foodsafety.gov and Government of Canada guidelines do not have a recommended reheating temperature, cooked 
products tested against these guidelines had their recommended temperature compared to their raw cooking temperature.

After these comparisons are done, a chi-squared test was performed on these factors: store the product was found in, cooked or uncooked, type of meat, if the product had safe handling instructions or not, and the guideline being compared to. This was done to see which of these factors had an effect on the frozen products passing or failing the guidelines.

\section{Results}

\section{Number of goods from Costco, Superstore, and $T \& T$ \\ (Refer to Table A)}

Superstore has the largest variety of products sampled, followed by Costco and T\&T. This is due to Costco having a much larger quantity of one type of product shelved compared to Superstore, and T\&T has a much smaller frozen food section compared to the other two. Products from Superstore tend to pass the recommendations of all three guidelines more than products from the other two stores, with even more products passing the $\mathrm{GoC}$ and Foodsafety.gov recommendations, likely due to the Food Code's higher poultry recommended temperature increasing the number of fails when being compared to that guideline. However, with the Foodsafety.gov standard, there were more passes than fails at Costco.

\section{Number of products from each type of meat group} (Refer to Table B)

A majority of the products are from the Poultry, Ground Meat, and Seafood groups. Ground meat products tend to have a recommended temperature of $74 \mathrm{C}$ while the Code recommends $70 \mathrm{C}$, so most of them pass (CFISIG, 2004; Foodsafety.gov, 2014;
GoC, 2014). The poultry products tend to have $74 \mathrm{C}$ as a recommended temperature as well, but the Code recommends $85 \mathrm{C}$ so most of them did not pass the Code. The ones that did pass were cooked and had a recommended temperature that met the reheating recommendation of $74 \mathrm{C}$. Also, most of the poultry products do meet GoC and Foodsafety.gov recommendations of 74 C. The seafood products mostly failed the Code and GoC because they did not have a recommended temperature at all anywhere on the packaging. However, the non-fin fish seafood products were not compared to the Foodsafety.gov recommendations as it does not have numerical standards to compare to. Despite this, a majority of the fin fish seafood products still failed to meet the standard because they were cooked but did not have a reheating temperature on the packaging.

\section{Number of products that are cooked or uncooked \\ (Refer to Table C)}

Most of the cooked products failed to meet the Code's recommendations was because they failed to list a recommended temperature at all. As mentioned previously, when reheating food, the Code recommends that the food achieves an internal temperature of $74 \mathrm{C}$. The majority of uncooked products that failed were the poultry products. As for the GoC and Foodsafety.gov, they did not have a standard reheating temperature, so the temperatures used for comparison against the cooked products were the temperatures recommended for that product's meat type when uncooked.

\section{Number of products with and without safe handling instructions (Refer to Table D)}

The products that did not have handling instructions tended to be cooked products. Both categories have more fails in their distribution of products that passed or 
failed the Code's or GoC's recommendations. However, due to eliminating some seafood products from the Foodsafety.gov analysis, the distribution was changed so that more passed this standard, meaning that a lot of the fails in the Code and GoC comparisons were from seafood products.

\section{Number of figures that meet or did not meet the guidelines}

(Refer to Table E)

There are more products that did not meet guidelines, and as previously mentioned, it is because either they did not list a reheating temperature on the cooked food, or most of the poultry products not having a recommended temperature of $85 \mathrm{C}$ when compared to the Code.

\section{Discussion}

The 2008 BCCDC study looked at 24 uncooked chicken nugget products, where only had 2 items without any recommended temperatures, and the rest recommend 71 to $77 \mathrm{C}$, which would mean they do not meet the Food Code guidelines (BCCDC, 2008). This is also true for all the uncooked poultry products found in this study. A possible reason for this is that the manufacturers used a different set of guidelines such as the federal one (GoC, 2014), and for good reason as at the Food Code's $85 \mathrm{C}$, the chicken would either be burnt or too dry to be palatable.

The Food Code does not specify if the listed temperature for poultry is for a whole chicken or for just a piece, while the federal temperature differentiates them. The federal chart recommends whole chickens be cooked to $85 \mathrm{C}$ and pieces of chicken be cooked to $74 \mathrm{C}$ (GoC, 2014). This study compared the recommended temperatures to the federal guidelines and Foodsafety.gov, and the results showed that on average, 18\% more of products passed these two other guidelines. This difference is most likely caused bt the poultry products not passing the Food Code.

A large number of products that did not meet guidelines were found to be cooked products, as they did not have a recommended cooking temperature on the packaging at all. The BCCDC study did not find this problem as they reviewed only uncooked products. This finding may mean that manufacturers did not take the danger of post-processing contamination into account, as well as the risk of a foodborne illness from inadequate reheating, the $4^{\text {th }}$ most likely cause of FBIs (Alberta Health Services, 2002). Another possible reason would be that the manufacturers assumed the consumers will follow the packaging's instructions step by step and therefore avoid any health hazards. If the products have been tested, then if the foods are cooked at the recommended oven or microwave temperature for the recommended amount of time, there would be no need for the consumer to check the temperature. However, if consumers did follow instructions properly all the time, then we would not have the previously mentioned outbreaks. The outbreaks mentioned in Appendix $\mathrm{H}$ - Table 1 were caused by inadequate cooking, but there is still the chance that common pathogens such as Listeria may contaminate the food after cooking and survive an inadequate reheating (FDA, 2012). This study looked at foods from different types of meat, and besides the aforementioned poultry issue, seafood products were also found to have problems in meeting all three guidelines. Again, this was due to most of the seafood products being cooked and not having a recommended reheating temperature.

The BCCDC study looked at the temperatures from products from different manufacturers, and products from Loblaws Inc., which are commonly found in Superstore, were found to be lacking safety due to not having safe food handling tips (BCCDC, 2008). This is no longer a problem 
as of this study, and overall, Superstore has proportionally more products meeting guidelines than Costco or T\&T. This may be due to the updated Meat Inspection Regulations being stricter (CFIA, 2013a). Another reason is that most of Superstore's products come from one manufacturer, Loblaws Inc., while Costco and T\&T obtain their products from numerous manufacturers, meaning they do not have a standardized packaging for their frozen products.

This study was also not able to assess the effectiveness of having safe handling instructions, recommended temperatures, a label saying the product is uncooked, or the cooking instructions provided, in preventing foodborne illnesses. The outbreaks mentioned in Appendix $\mathrm{H}$ - Table 1 were caused by 'misleading instructions', but it is unknown which part of the listed factors above made it confusing. As this study is only an audit, it was also unable to test how likely customers would be using a thermometer to check the products' temperatures.

\section{Limitations}

The statistical analysis may be skewed for the Foodsafety.gov guideline because non- fin fish seafood items were included from the chi-squared test for that guideline. This is due to that guideline not having a numerical recommended temperature for non- fin fish seafood.

The 2008 BCCDC study was able to look at different brands from various stores, but this study was only able to look at three stores due to lack of time and personnel available. On the other hand, this study was able to look at many more and a larger variety of products, but they are limited only to the manufacturers that sell food to Superstore, Costco, or T\&T. The amount of products from each meat type are also uneven, which may also skew results

The scope of this study was limited to the recommended temperature on product packaging. The BCCDC study also looked at what kinds of safe handling instructions were provided and whether there were pathogens on the food. Due to lack of time, equipment, training and funding, these two factors were out of the scope of this study.

Most of the products from T\&T were cooked products and had no reheating temperatures, which added many products that failed to meet guidelines. This was a smaller T\&T, which means that other locations may have a larger selection of products, including uncooked products.

\section{Recommendations}

One of the possible reasons the aforementioned FBI events occurred was due to confusing cooking instructions, so to avoid repeat incidences the government should take action in making cooking instructions standardized to avoid illnesses caused by poorly worded instructions. The government should also choose a guideline to base recommended temperatures on, or create a new standard for temperatures to avoid the confusion of having several guidelines with different temperatures.

There should be a legal requirement to put recommended temperatures on cooked products, due to the fact that a majority of the cooked products sampled did not provide one, and because of the possibility of post processing contamination and inadequate reheating leading to a FBI (AHS, 2002).

Another possible reason for an FBI occurring would be from the customer not knowing that the product is uncooked, and thus thought light microwaving would be enough to cook the food and kill all pathogens on it. While gathering data, the researcher found that the 'uncooked/raw' statement were in small font and sometimes difficult to locate. Manufacturers should make these statements more visible.

Finally, education and knowledge is a good base for prevention. Customers should be educated on what temperatures are safe and to use thermometers to check their food, 
as well as to look for the 'uncooked' statement, the recommended temperature, and safe handling instructions when cooking frozen products. The manufacturers should also be educated on the danger of postprocessing contamination and inadequate reheating as that was the biggest problem with cooked products.

\section{Future Research}

For future studies beyond the scope of this project, there are several directions to take. One would be to continue looking at more frozen products of different types and brands, and from different stores, to see if they do meet guidelines. However, recommended temperatures are just one aspect of preventing a FBI from frozen products, so other factors must be researched as well.

This study was only able to look from the customer's point of view, but a study on what manufacturers base their cooking instructions and temperatures on would be beneficial in finding out why people have problems following their instructions. On the other hand, a survey of what customers look at on the packaging and what steps they take to ensure food safety when cooking their frozen food may also hold answers to this problem. It is beyond the scope of this study to find out the level of knowledge manufacturers and customers have regarding the food safety of frozen foods.

\section{Conclusion}

The federal Meat Inspection Regulations gives the requirement for manufacturers to put cooking instructions for customers with the intent of preventing foodborne illness (CFIA, 2013a). However, it is clear from the mentioned incidents that these instructions may sometimes be lacking. There could be several reasons as to why: there are several guidelines to base instructions on, customers lack the motivation for or understanding of achieving food safety, or the instructions were simply lacking. It was found that most uncooked products of the ground meat, beef and pork types are good with meeting guidelines, except for poultry and the Food Code, and it can also be speculated that many of the frozen products not sampled would be similar in their compliance. Using only the Food Code and Government of Canada guidelines, the same can be said for seafood as well.

This study was performed with the intent of increasing the numeric scope of the BCCDC 2008 study by looking at the recommended temperatures of more products. The information was intended to be used as a basis for actions for Environmental Health Officers to take a stance regarding the information found on the packaging on frozen meat products.

EHOs employed by the CFIA in manufacturing plants are responsible for setting the recommended temperatures on packaging (Wong, Albert, personal communication). However, provincial level EHOs have no legislative powers in the matter of setting recommended temperatures.

EHOs do, however, have a mandate to prevent diseases from occurring and education of the public is one way to achieve that. Using the information found in this study, health promotion campaign can be held to warn consumers to look at the label of certain frozen products before cooking and to follow the safe handling and cooking instructions, or a public message can be spread to tell consumers how to cook certain products if their packaging has unclear instructions. By knowing which products could potentially cause an outbreak through unclear cooking instructions, CFIA EHOs may be able to prepare for recalls better if a suspect product caused an outbreak, as well as doing a public notice to warn the public to avoid the product. 


\section{References}

Alberta Health Services (2002). Top

improper food handling practices and

common job hazards.

Retrieved from

http://www.calgaryhealthregion.ca/pu

blichealth/envhealth/program_areas/food_saf

ety/ documents/FSTop.pdf

BCIT. (2011). Procedures for implementing the BCIT research ethics policy. Retrieved from

http://www.bcit.ca/files/pdf/bcit_proc

edures_research_ethics_for_human_subject.p

df

British Columbia Center for Disease Control. (2008). Surveillance of Frozen Processed

Chicken Products in BC - May 2008.

British Columbia Center for Disease Control. (2009). Ensuring Food Safety.

British Columbia Center for Disease Control. (2012a). Campylobacter. Retrieved from http://www.bccdc.ca/dis-cond/az/_c/Campylobacter/overview/Campylobacter .htm

British Columbia Center for Disease Control. (2012b). Listeria/Listeriosis. Retrieved from http://www.bccdc.ca/dis-cond/az/_l/Listeria/default.htm

British Columbia Center for Disease Control. (2012c). Salmonella infection. Retrieved from

http://www.bccdc.ca/dis-cond/a z/_s/SalmonellaInfection/overview/S

almonella+Infection.htm

British Columbia Center for Disease Control. (2012d). Salmonella enteritidis investigation.

Retrieved From

http://www.bccdc.ca/dis-cond/a$\mathrm{z} /$ s/SalmonellaInfection/SEInvestiga tion/default.htm
Canadian Food Inspection Agency. (2013a).

Meat Inspection Regulations, 1990.

(Publication No. SOR/90-288). Retrieved from

http://laws-

lois.justice.gc.ca/eng/regulations/SOR-90288/page-25.html\#docCont

Canadian Food Inspection Agency. (2013b). Anned D: Cooking time/ temperature tables. Retrieved from http://www.inspection.gc.ca/food/meat-andpoultry-products/manual-ofprocedures/chapter-4/annexd/eng/1370527526866/1370527574493

Canadian Food Inspection System Implementation Group. (2004). Food Retail and Food

Services Code. Retrieved from http://foodsafe.ca/resources/Food_Services_C ode2004.pdf

Centers for Disease Control and Prevention. (2008). Multistate outbreak of Salmonella infections associated with frozen pot pies United States, 2007. Retrieved from http://www.cdc.gov/mmwr/preview/ mmwrhtml/mm5747a3.htm

Centers for Disease Control and Prevention. (2013). Campylobacter. Retrieved from http://www.cdc.gov/nczved/divisions /dfbmd/diseases/campylobacter/

Fayerman, P. (2004, June). Frozen nuggets pose risk of salmonella, study says.

Vancouver Sun, p. A1.

Food and Drug Administration. (2012). Bad Bug Book, Foodborne Pathogenic Microorganisms and Natural Toxins. Second Edition.

Food and Drug Administration. (2013). Food code. Retrieved from 
http://www.fda.gov/downloads/Food/ GuidanceRegulation/RetailFoodProtection/Fo odCo de/UCM374510.pdf

Foodsafety.gov. (2014). Safe minimum cooking temperatures. Retrieved from http://www.foodsafety.gov/keep/char ts/mintemp.html

Government of Canada (2014). Safe internal cooking temperatures. Retrieved from http://healthycanadians.gc.ca/eatingnutrition/safety-salubrite/cook-temperaturescuisson-eng.php

Heacock, H., Sidhu, B. (2013a). Research methods module 5: Descriptive statistics. Personal Collection of H. Heacock \& B. Sidhu, BCIT, Burnaby, BC.

Heacock, H., Sidhu, B. (2013b). Research methods module 5: Inferential statistics. Personal Collection of H. Heacock \& B. Sidhu, BCIT, Burnaby, BC.

Health Canada. (2012). Safe internal cooking temperatures. Retrieved from http://healthycanadians.gc.ca/eatingnutrition/safety-salubrite/cook-temperaturescuisson-eng.php

MacDougall, L., Fyfe, M., McIntyre, L., Paccagnela, A., Cordner, K., Kerr, A., Aramini, J. (2004).

Frozen Chicken Nuggets and Strips-A Newly Identified Risk Factor for Salmonella Heidelberg Infection in
British Columbia, Canada. Journal of Food Protection, 67, 1111- 1115.

MedlinePlus. (2013a). Salmonella infection.

Retrieved from

http://www.nlm.nih.gov/medlineplus/ salmonellainfections.html

MedlinePlus. (2013b). Listeria infection.

Retrieved from http://www.nlm.nih.gov/medlineplus/ listeriainfections.html

Medscape. (2010). Multistate outbreak of Salmonella Chester infections associated with frozen meals. Retrieved from http://www.medscape.com/viewarticle/81776 0

Microsoft. (2007a). Microsoft Excel 2007. Redmond, Washington: Microsoft

Microsoft. (2007b). Microsoft Word 2007. Redmond, Washington: Microsoft

NCSS: Statistical \& Power Analysis Software (2013). Accessed, November 14, 2013.

Website: http://www.ncss.com

USDA. (2003). Restaurant X: Food safety manual. Retrieved from http://www.fda.gov/downloads/Food/ FoodSafety/RetailFoodProtection/Industryan dRegu latoryAssistanceandTrainingResourc es/UCM088896.pdf

Table A: Products from each store

\begin{tabular}{|l|l|r|r|r|r|r|r|}
\hline & & \multicolumn{1}{|c|}{$\begin{array}{l}\text { Food Services } \\
\text { Code }\end{array}$} & \multicolumn{2}{c|}{$\begin{array}{l}\text { Government of } \\
\text { Canada }\end{array}$} & \multicolumn{2}{|c|}{ Foodsafety.gov } \\
\hline & $\begin{array}{l}\text { \# of } \\
\text { products } \\
\text { from each } \\
\text { store }\end{array}$ & Pass & Fail & Pass & Fail & Pass & Fail \\
\hline Store & 56 & 16 & 40 & 24 & 32 & 25 & 20 \\
\hline Suptco & 111 & 61 & 50 & 91 & 20 & 89 & 13 \\
\hline T\&T & 41 & 8 & 33 & 8 & 33 & 8 & 31
\end{tabular}




\begin{tabular}{|l|l|l|l|l|l|l|l|}
\hline Total & & 85 & 123 & 123 & 85 & 122 & 64 \\
\hline
\end{tabular}

Table B: Products in each type of meat category

\begin{tabular}{|c|c|c|c|c|c|c|c|}
\hline \multirow[b]{2}{*}{ Type of Meat } & \multirow[b]{2}{*}{$\begin{array}{l}\text { \# of } \\
\text { products }\end{array}$} & \multicolumn{2}{|c|}{$\begin{array}{c}\text { Food Services } \\
\text { Code }\end{array}$} & \multicolumn{2}{|c|}{$\begin{array}{c}\text { Government of } \\
\text { Canada }\end{array}$} & \multicolumn{2}{|c|}{ Foodsafety.gov } \\
\hline & & Pass & Fail & Pass & Fail & Pass & Fail \\
\hline Beef & 13 & 8 & 5 & 8 & 5 & 8 & 5 \\
\hline Ground Meat & 48 & 45 & 3 & 45 & 3 & 45 & 3 \\
\hline Pork & 28 & 9 & 19 & 8 & 20 & 9 & 19 \\
\hline Poultry & 65 & 9 & 56 & 50 & 15 & 50 & 15 \\
\hline Seafood & 54 & 13 & 41 & 12 & 42 & 10 & 22 \\
\hline Total & & 84 & 124 & 123 & 85 & 122 & 64 \\
\hline
\end{tabular}

Table C: Cooked or Uncooked Products

\begin{tabular}{|l|l|r|r|r|r|r|r|}
\hline & & \multicolumn{2}{|c|}{$\begin{array}{l}\text { Food Services } \\
\text { Code }\end{array}$} & \multicolumn{2}{c|}{$\begin{array}{l}\text { Government of } \\
\text { Canada }\end{array}$} & \multicolumn{2}{c|}{ Foodsafety.gov } \\
\hline Meat status & $\begin{array}{l}\text { \# of } \\
\text { products }\end{array}$ & \multicolumn{1}{|c|}{ Pass } & \multicolumn{1}{l|}{ Fail } & \multicolumn{1}{c|}{ Pass } & \multicolumn{1}{l|}{ Fail } & \multicolumn{1}{l|}{ Pass } & \multicolumn{1}{l|}{ Fail } \\
\hline Cooked & 96 & 29 & 67 & 30 & 66 & 27 & 51 \\
\hline Uncooked & 112 & 55 & 57 & 97 & 26 & 95 & 13 \\
\hline Total & & 84 & 124 & 127 & 92 & 122 & 64 \\
\hline
\end{tabular}

Table D: Products with or without safe handling instructions

\begin{tabular}{|c|c|c|c|c|c|c|c|}
\hline \multirow[b]{2}{*}{$\begin{array}{l}\text { Availability of } \\
\text { Instructions }\end{array}$} & \multirow[b]{2}{*}{$\begin{array}{l}\text { \# of } \\
\text { products }\end{array}$} & \multicolumn{2}{|c|}{$\begin{array}{c}\text { Food Services } \\
\text { Code }\end{array}$} & \multicolumn{2}{|c|}{$\begin{array}{c}\text { Government of } \\
\text { Canada }\end{array}$} & \multicolumn{2}{|c|}{ Foodsafety.gov } \\
\hline & & Pass & Fail & Pass & Fail & Pass & Fail \\
\hline $\begin{array}{l}\text { no handling } \\
\text { instructions }\end{array}$ & 45 & 22 & 23 & 19 & 26 & 26 & 16 \\
\hline $\begin{array}{l}\text { w/ handling } \\
\text { instructions }\end{array}$ & 163 & 62 & 101 & 66 & 97 & 97 & 48 \\
\hline Total & & 84 & 124 & 85 & 123 & 123 & 64 \\
\hline
\end{tabular}


Table E: Pass or Fail from standards used

\begin{tabular}{|l|l|r|r|}
\hline Standards Used & \# of products & Pass & \multicolumn{1}{|c|}{ Fail } \\
\hline $\begin{array}{l}\text { Food Retail \& } \\
\text { Food Services } \\
\text { Code }\end{array}$ & 208 & 84 & 124 \\
\hline $\begin{array}{l}\text { Government of } \\
\text { Canada }\end{array}$ & 208 & 123 & 85 \\
\hline Foodsafety.gov & 186 & 122 & 64 \\
\hline
\end{tabular}

